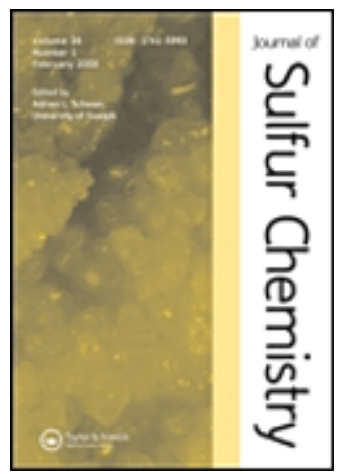

\title{
New polymeric sulfide-borane complexes: convenient hydroborating and reducing reagents
}

\begin{tabular}{|c|c|}
\hline Journal: & Journal of Sulfur Chemistry \\
\hline Manuscript ID: & Draft \\
\hline Manuscript Type: & Research Article \\
\hline $\begin{array}{r}\text { Date Submitted by the } \\
\text { Author: }\end{array}$ & $\mathrm{n} / \mathrm{a}$ \\
\hline Complete List of Authors: & $\begin{array}{l}\text { El-Hiti, Gamal; Cardiff University, School of Chemistry } \\
\text { Smith, K; Cardiff University } \\
\text { Balakit, Asim; Cardiff University, Chemistry } \\
\text { Pardasani, R; University of Rajasthan }\end{array}$ \\
\hline Keywords: & $\begin{array}{l}\text { polysulfides, borane adducts, hydroboration, reduction, carbonyl } \\
\text { compounds }\end{array}$ \\
\hline \multicolumn{2}{|c|}{$\begin{array}{l}\text { Note: The following files were submitted by the author for peer review, but cannot be converted } \\
\text { to PDF. You must view these files (e.g. movies) online. }\end{array}$} \\
\hline $\begin{array}{l}\text { Scheme } 1 . c d x \\
\text { Scheme } 2 . c d x \\
\text { Scheme } 3 . c d x \\
\text { Graphical Abstract.doc } \\
\text { Tables.doc }\end{array}$ & \\
\hline
\end{tabular}

\section{SCHOLARONE Manuscripts}




\title{
New polymeric sulfide-borane complexes: convenient hydroborating and reducing reagents
}

\author{
Keith Smith, ${ }^{* a}$ Asim A. Balakit, ${ }^{a}$ Ramchand T. Pardasani ${ }^{b}$ and Gamal A. El-Hiti ${ }^{*^{a+}}$ \\ ${ }^{a}$ School of Chemistry, Cardiff University, Main Building, Park Place, Cardiff UK CF10
}

3AT._E-mail:_smithk13@cardiff.ac.uk, el-hitiga@cardiff.ac.uk; ${ }^{b}$ Department of Chemistry, University of Rajasthan, Jaipur - 302 055, India 


\title{
K. Smith et al.
}

\begin{abstract}
New polymeric borane adducts have been synthesized from polymeric sulfides, which are solids with a minimal odour. The adducts contain a high concentration of borane, have significant stability and are soluble in THF. They act as hydroborating and reducing reagents with behaviour similar to that of borane-methyl sulfide, making them attractive borane sources.
\end{abstract}

Keywords: polysulfides, borane adducts, hydroboration, reduction, carbonyl compounds

\section{Introduction}

Borane complexes are highly versatile reagents with numerous applications in organic syntheses and industrial processes (1-3). The most commonly used are boranetetrahydrofuran ( $\mathrm{BH}_{3}$.THF) (4) and borane-dimethyl sulfide $\left(\mathrm{BH}_{3} \cdot \mathrm{SMe}_{2}, \mathrm{BMS}\right)$ (5). However, both these reagents possess certain unfavourable characteristics (5). $\mathrm{BH}_{3}$. THF is commercially available only as a dilute solution, $1.0 \mathrm{M}$ in $\mathrm{BH}_{3}$, and it also undergoes slow cleavage of THF at room temperature. BMS is free from these disadvantages, as it is a neat complex, 10.0 M in $\mathrm{BH}_{3}$, can be used in a variety of solvents and is highly stable. However, BMS liberates a stoichiometric amount of water-insoluble dimethyl sulfide, which has an obnoxious odour, high volatility and inflammability, thereby creating environmental and safety problems, particularly for large scale use. This prompted Brown and co-workers ( 6 ) in 1992 to introduce 1,4-oxathiane as a less volatile carrier for borane. Subsequently, the Brown group demonstrated the utility of a series of liquid organic sulfides (7) as borane carriers, bis(hydroxymethyl)sulfide (8) possessing the additional advantage of being water soluble. More recently, Crich et al. (9) have described 2-(perfluorooctyl)ethyl methyl sulfide as a recyclable borane carrier. A few solid borane complexes with bis-sulfides $(2 a)$ have also been patented. Clearly there is a strong desire for safe borane carriers that can be easily handled. However, to be attractive as replacements for the commonly used complexes, alternative adducts must be fairly high in borane content (to avoid having to transport large quantities), be stable enough for long term storage, have distinct advantages in terms of handling (e.g. avoiding obnoxious odours, avoiding high flammability or allowing easy recovery of the carrier), be relatively inexpensive, and match borane-THF or BMS in terms of reactivity profile. To date, no other complex has fulfilled these criteria sufficiently well to rival the common complexes.

Polymer-bound borane complexes offer the possibility of stable and easily handled materials of low volatility, with minimal odour and with easily recoverable polymeric 
carrier. Indeed, a number of polymer-bound complexes have been reported, including $\mathrm{BH}_{3}$ complexes of several cross-linked polymeric sulfides (10), a cross-linked poly(4-vinylpyridine)-borane complex in which the borane content was up to $7.8 \mathrm{mmol} / \mathrm{g}$ (11), and borane and haloborane complexes of poly(propylene sulfide) grafted onto crossliked polystyrene (12). Although all of these reagents have been used for hydroboration of alkenes and/or reduction of aldehydes and ketones to produce the corresponding alcohols, acid catalysis was required in the case of the poly(vinylpyridine) complex (13). Thus, its reactivity profile is significantly different (and less useful) than that of borane-THF or BMS, so it cannot be viewed as a potential replacement. A similar situation pertains with polymer-supported ethylenediamine borane complexes prepared using a Merrifield resin or a 1,6-hexanediol diacrylate-cross-linked polystyrene resin (14). These materials have been used for reduction of aldehydes to the corresponding alcohols in high yields at room temperature, but the concentration of borane in the complexes is already low and the use of a two molar excess of the polymeric reagent was required (14). However, the polymer could be regenerated easily and reused without loss in reactivity.

The borane content of the grafted poly(propylene sulfide) complex was also low (around $2.44 \mathrm{mmol} \mathrm{BH}_{3} / \mathrm{g}$ ) (12). A higher borane content (up to $7.05 \mathrm{mmol} \mathrm{BH}_{3} / \mathrm{g}$ of polymer) was claimed for a homo (polypropylene sulfide) complex, but this material was prepared and used only as a dilute solution in dichloromethane and it is not clear whether removal of the solvent would have left a solid with such a high concentration of borane (12). There are no reports of these complexes ever having been utilised, possibly because of the low borane content of the solid borane-polymer complex and the inconvenience of transporting a dilute solution of the homo poly(propylene sulfide)-borane complex.

Our long-standing interests in the use of solids in green methodologies (15) and in boron chemistry (16) led us to consider the possibility of other polymeric sulfides as suitable borane carriers. In particular, we wished to develop complexes possessing high molarity in $\mathrm{BH}_{3}$, based on solids that are easy to prepare, convenient to handle, have mild odour and low volatility, and are environmentally benign. We now report the results of our efforts to develop such reagents.

\section{Results and Discussion}

Polymeric sulfides 1-6 were synthesised based on literature procedures (17). Unlike poly(propylene sulfide) these contain unbranched alkylene chains. The complexing ability of the polymers towards borane was investigated by bringing them into contact with 
K. Smith et al.

$\mathrm{BH}_{3}$.THF or diborane gas using four procedures: (i) reaction of neat solid sulfide 1-6 with $\mathrm{BH}_{3}$.THF; (ii) reaction of neat polymer with diborane gas; (iii) reaction of a solution of the polymeric material with $\mathrm{BH}_{3}$.THF; and (iv) reaction of a solution of the polymeric material with diborane gas. Interestingly, and uniquely, no uptake of borane to give complex 7 was observed for the sulfide $\mathbf{1}(\mathrm{n}=2)$ under any of the conditions tried. This was surprising in view of the reported uptake of up to $7 \mathrm{mmol} / \mathrm{g}$ of borane by poly(propylene sulfide), which is simply a methyl-substituted version of this polymer. The other linear polymeric sulfides (2-6) all absorbed significant quantities of borane by all of the procedures, and, after considerable experimentation it was found that passage of diborane gas, generated from $\mathrm{BF}_{3} \cdot \mathrm{OEt}_{2}$ and sodium borohydride (18), into a solution of the polymeric sulfide $(3 \mathrm{~g})$ in dichloromethane $(20 \mathrm{~mL})$ at room temperature was the most convenient method for producing the corresponding borane adducts 8-12 (Scheme 1). In this procedure the adducts precipitated, but were not separated by filtration or decantation. Instead, the solvent was removed by blowing nitrogen over the mixture to leave the solid adducts. Table 1 gives their borane content and ${ }^{11} \mathrm{~B}$ NMR data.

\section{Scheme 1 here}

Table 1 here

The effect of other solvents in this procedure was also tested. Adducts resulting from reaction in chloroform or diglyme possessed a hydride content that was lower by about $10 \%$ than for complexes formed in dichloromethane. Use of more dilute dichloromethane solutions also resulted in lower hydride content of the precipitated complexes. The gas analysis of adducts 8-12 indicated that around two-thirds of the total sulfur atoms had been coordinated with borane. The ${ }^{11} \mathrm{~B}$ NMR spectra of all complexes showed a single resonance at $\delta-20.8$ to $-20.9 \mathrm{ppm}$ consistent with the formation of the adducts.

The borane adducts 8-12 were white powders at room temperature and exhibited a very mild 'borane' odour when transferred in air. They were soluble in THF, which is typically used for hydroboration and reduction reactions. They appeared to be stable over long periods under nitrogen (there was no change in borane content after three weeks at room temperature under nitrogen and no visible change even after one year under nitrogen). They were fairly stable even in air, decomposing only slowly on standing in air 


\section{Table 2 here} peaks at 2398 and $1095 \mathrm{~cm}^{-1}$, which may be attributed to B-H and B-S stretching vibrations, respectively (19), appeared in the spectra of freshly prepared pure samples of the complexes. No peak around $3200 \mathrm{~cm}^{-1}$ corresponding to boric acid was observed initially. After samples had stood for 4 hours in air the peaks at 2398 and $1095 \mathrm{~cm}^{-1}$ began to diminish noticeably and a strong peak around $3200 \mathrm{~cm}^{-1}$ began to appear, thereby indicating hydrolysis of the adduct. On prolonged standing the solid began to darken. This significant stability enabled the solid borane adducts to be weighed on a simple balance without protection from air. Their very mild odours were further indication that they did not release borane readily. These features and their reasonable solubilities make them potentially attractive and easy-to-handle reagents.

To establish the synthetic applicability of the new borane complexes, hydroboration-oxidation of alkenes was studied. Initially hydroboration-oxidation of 1-octene (Scheme 2; $\mathrm{R}=n-\mathrm{C}_{6} \mathrm{H}_{13}$ ) in THF at room temperature was conducted with the borane adducts 8-12 for $4 \mathrm{~h}$. In each case a high yield (by GC) of a mixture of 1- and 2-octanol was obtained, indicating that the reactivities of the new borane adducts were comparable to those of BMS (4) and $\mathrm{BH}_{3}$-THF (20). Thus, hydroboration of other representative alkenes was conducted initially with $\mathbf{8}$ as the borane adduct (Scheme 2). Adduct 8 was chosen because its polymer's repeating unit has the lowest relative mass, so that its borane content is higher in mass terms than the others. The results are recorded in Table 2.

\section{Scheme 2 here}

The procedure involved addition of an alkene $(9.0 \mathrm{mmol})$ to the solution of borane complex $\left(3.6 \mathrm{mmol}\right.$ of $\mathrm{BH}_{3}$ ) in THF at $0-5{ }^{\circ} \mathrm{C}$ followed by stirring for $4 \mathrm{~h}$ and then oxidative work up with alkaline hydrogen peroxide. The alcohols produced were analysed by GC. The yields of alcohols obtained were in the range of 61-86\%.

A series of experiments was conducted in order to find conditions under which higher yields of alcohols could be obtained. It was found that use of a longer reaction time 


\section{K. Smith et al.}

(16 h) gave satisfactory results. Therefore, the procedure was applied to a range of alkenes. The results obtained are recorded in Table 3.

Table 3 here

Reactions conducted over this longer reaction period gave good yields (84-99\%). The regioselectivities of hydroboration of 1-hexene and styrene were similar to those reported for BMS (5) and $\mathrm{BH}_{3}$-THF (21). Thus, hydroboration of 1-hexene formed 1- and 2-hexanols in the ratio of 84:4, while styrene gave 1- and 2-phenylethanols in the ratio 79:12. Hydroboration of 1-methylcyclohexene produced trans-2-methylcyclohexanol in essentially quantitative yield. The adduct 8 therefore functioned very similarly to BMS in hydroboration reactions, but with the significant advantage that the reactions are odour free and do not liberate dimethyl sulfide.

To establish further the synthetic potential of the new borane adduct $\mathbf{8}$, reduction of representative organic functional groups was studied (e.g. Scheme 3 for reduction of aldehydes and ketones) and the results are recorded in Table 4.

\section{Scheme 3 here}

Table 4 here

The procedure adopted was to add a standard solution of the organic compound in THF to an appropriate quantity of complex in THF at $0{ }^{\circ} \mathrm{C}$ and then reflux the mixture for $4 \mathrm{~h}$. The excess borane was then quenched with methanol and the product was analysed by GC. Reduction of most substrates was straightforward and gave high yields (85-100\%) of the corresponding alcohols, similar to $\operatorname{BMS}(21,22)$. Although the reactions were carried out under standard conditions of reflux for $4 \mathrm{~h}$, such forcing conditions were often not necessary. However, the reduction of benzamide was slow and only a $66 \%$ yield of benzylamine was obtained even after a longer reaction time (16 h).

The sulfide polymer could be recovered following either hydroboration or reduction reactions. The polymeric material 2 was precipitated as a white solid by the addition of diethyl ether during the work-up process and was removed by filtration. It was washed with a saturated solution of sodium hydroxide to remove any boric acid, then washed thoroughly with water and left to dry in a vacuum oven. The recovered polymer 
was reused again to prepare $\mathbf{8}$. The adduct obtained was virtually identical to the initial one. It had the same borane content and showed the same behaviour when used as a hydroborating and reducing agent.

Our attention was next turned to use of borane adduct 11, to test whether it showed any significant differences in activity compared to 8. Adduct $\mathbf{1 1}$ was tested in hydroboration of representative alkenes and reduction of representative carbonyl compounds under conditions similar to those used with adduct 8 (Schemes 2 and 3, respectively). The results obtained are recorded in Tables 5 and 6, respectively.

Table 5 here

The results recorded in Table 5 clearly indicated that adduct $\mathbf{1 1}$ can be used as a hydroborating agent. The small variations in yields obtained compared with those obtained from similar reactions involving use of adduct 8 may be due to losses during work-up. However, the selectivities observed were entirely comparable. For example, hydroboration of 1-octene produced a mixture of 1- and 2-octanols in 77 and 4\% yields, respectively, compared to 81 and $4 \%$, respectively, with adduct $\mathbf{8}$. Similarly with styrene, 1- and 2-phenylethanols were formed in the ratio of 84:13, similar to the 79:12 ratio obtained with adduct 8 ).

Table 6 here

Table 6 shows that adduct $\mathbf{1 1}$ can also be used as a reducing reagent for various carbonyl compounds to produce the corresponding alcohols in high yields (84-100\%). Again, the reactions were carried out under standard conditions at reflux for $4 \mathrm{~h}$, although not all examples needed such forcing conditions.

\section{Conclusions}

In conclusion, borane adducts derived from polymeric sulfides are solids of high hydride content that can be readily weighed in air. Their mild smell, good solubility in THF, and reactivity comparable to that of BMS, make them attractive borane sources. Consequently, complex $\mathbf{8}$, in particular, is a highly promising, new hydroborating reagent, which might well be suitable for large scale industrial application. 
K. Smith et al.

\section{Experimental Section}

General. All reactions were performed under a nitrogen atmosphere. Glassware was oven dried, assembled hot and allowed to cool under a stream of nitrogen gas. All reagents were purchased from commercial sources and used as received. THF was distilled from sodium benzophenone ketyl and other solvents were purified by standard procedures (23). Infrared spectra were recorded on a Perkin Elmer Spectrum One FT-IR spectrometer. ${ }^{1} \mathrm{H}$ and ${ }^{11} \mathrm{~B}$ NMR spectra were recorded on a Bruker AV400 spectrometer operating at $400 \mathrm{MHz}$ for ${ }^{1} \mathrm{H}$ or $128 \mathrm{MHz}$ for ${ }^{11} \mathrm{~B}$ measurements. Chemical shifts $\delta$ are reported in parts per million (ppm) relative to TMS and $\mathrm{BF}_{3} \cdot \mathrm{Et}_{2} \mathrm{O}$, respectively. GC analyses were carried out on a Shimadzu Gas Chromatograph fitted with a ZEBRON ZB-5 (5\% phenyl polysiloxane) $30 \mathrm{~m}$ length column. The GC conditions used for analysis were: $40{ }^{\circ} \mathrm{C}$ for 1 min, ramped to $250{ }^{\circ} \mathrm{C}$ at $20{ }^{\circ} \mathrm{C} / \mathrm{min}$ and held for $3 \mathrm{~min}$. The injection temperature was $250{ }^{\circ} \mathrm{C}$ and the detection temperature $250{ }^{\circ} \mathrm{C}$. Hexadecane was used as a GC standard. Microanalyses were performed by Warwick analytical service at the University of Warwick.

\section{Borane adducts: typical experimental procedure for preparation of borane adduct 8}

Diborane gas generated by reaction of sodium borohydride (5.67 g, $0.15 \mathrm{~mol}$ ) in diglyme (50 mL) with $\mathrm{BF}_{3} . \mathrm{Et}_{2} \mathrm{O}(24.5 \mathrm{~mL}, 0.20 \mathrm{~mol})$ was passed slowly through a dichloromethane (25 mL) solution of polymeric sulfide 2 (3.0 g) at room temperature over a period of $2 \mathrm{~h}$. Excess diborane was allowed to absorb in THF $(15 \mathrm{~mL})$ in a second bubbler. A white solid precipitated out in the flask containing the polymer when passage of the borane gas was nearing completion. The solvent was removed from the mixture by blowing with nitrogen. The resulting borane-sulfide adduct 8 was analysed for active hydride by a standard procedure (24) using THF:glycerol:3 $\mathrm{M} \mathrm{HCl} \mathrm{(1:1:1)} \mathrm{as} \mathrm{the} \mathrm{hydrolysing} \mathrm{mixture.} \mathrm{The} \mathrm{ratio}$ of $\mathrm{BH}_{3}$ units to $S$ atoms in the polymer was $c a$ 0.68. $\delta_{\mathrm{B}}\left(128 \mathrm{MHz}, \mathrm{CDCl}_{3} ; \mathrm{Me}_{4} \mathrm{Si}\right)-20.9$.

\section{Hydroboration-oxidation of alkenes: typical procedure for hydroboration of 1-hexene with 8}

In an oven dried $50 \mathrm{~mL}$ flask protected by a rubber septum was placed 8 (0.44 g, $3.6 \mathrm{mmol}$ $\mathrm{BH}_{3}$ ). The flask was cooled to $0{ }^{\circ} \mathrm{C}$ under a stream of nitrogen and freshly distilled THF (14 mL) was added. 1-Hexene (0.757 g; $9.0 \mathrm{mmol})$ was added and the mixture was stirred at $0{ }^{\circ} \mathrm{C}$ for $30 \mathrm{~min}$ and then at room temperature for $16 \mathrm{~h}$. The reaction mixture was cooled 
to $0{ }^{\circ} \mathrm{C}$ and $\mathrm{NaOH}(3.0 \mathrm{M}, 3.0 \mathrm{~mL})$ was added, followed by slow addition of hydrogen peroxide (30\%, $3.5 \mathrm{~mL}$ ). The contents were further stirred at room temperature for $1 \mathrm{~h}$ to ensure complete oxidation. Hexadecane $(0.75 \mathrm{~g})$ was added followed by addition of diethyl ether $(10 \mathrm{~mL})$ to precipitate the liberated polymeric sulfide. GC of the organic layer showed that the combined yield of 1- and 2-hexanols was 84\% in ca 80:4 ratio.

\section{Reduction of functional groups: typical procedure for reduction of benzaldehyde with 8}

A $50 \mathrm{~mL}$ two neck flask equipped with a reflux condenser and a magnetic bar was flushed with nitrogen and charged with $8\left(0.24 \mathrm{~g}, 2.0 \mathrm{mmol} \mathrm{BH}_{3}\right)$ and cooled to $0{ }^{\circ} \mathrm{C}$. THF (10 $\mathrm{mL}$ ) was added and the resulting colourless solution was cooled to $0{ }^{\circ} \mathrm{C}$. Benzaldehyde (0.53 g; $5.0 \mathrm{mmol}$ ) was then added dropwise. The reaction mixture was stirred at $0{ }^{\circ} \mathrm{C}$ for $30 \mathrm{~min}$ and a further $4 \mathrm{~h}$ under reflux conditions. The flask was then cooled to $0{ }^{\circ} \mathrm{C}$ and methanol ( $3 \mathrm{~mL}$ ) was added to quench any excess borane. Subsequently, diethyl ether (10 $\mathrm{mL}$ ) was added to precipitate the released polymeric sulfide. GC analysis of the organic layer showed the formation of benzyl alcohol (100\%). The organic layer from the reaction was washed with brine ( $3 \times 20 \mathrm{~mL}$ ), and most of the solvent was removed under vacuum. Hexane $(10 \mathrm{~mL})$ and ether $(10 \mathrm{~mL})$ were added to the residue, which precipitated further polymeric material. The polymer was filtered off and the filtrate was dried $\left(\mathrm{MgSO}_{4}\right)$. The solvent was removed under reduced pressure to give benzyl alcohol (0.0.45 g, $4.17 \mathrm{mmol}$; $83 \%$ ) as a colourless oil identical to an authentic sample.

\section{Acknowledgements}

We thank the Iraqi Government and Cardiff University for financial support.

\section{References}

(1) (a) Pelter, A.; Smith, K.; Brown, H.C. Borane Reagents, Academic Press, London, 1988. (b) Ramachandran, P.V.; Brown, H.C. Organoboranes for Syntheses, American Chemical Society, Distributed by Oxford University Press, Washington DC, 2001.

(2) (a) Follet, M. Chem. Ind., 1986, 123-128. (b) Lane, C.F. Aldrichim. Acta 1973, 6, 51-58. (c) Potyen, M.; Josyula, K.V.B.; Schuck, M.; Lu, S.; Gao, P.; Hewitt, C. Org. Process Res. Dev. 2007, 11, 210-214. 
K. Smith et al.

(3) (a) Brown, H.C.; Heim, P.; Yoon, N.M. J. Am. Chem. Soc. 1970, 92, 1637-1646.

(b) Zaidlewicz, M.; Brown, H.C. In Encyclopedia of Reagents for Organic Synthesis (EROS), ed. Paquette, L.A., Wiley, Chichester, UK, 1995, Vol 1.

(4) (a) Brown, L.M.; Brown, R.A.; Crissman, H.R.; Opperman, M.; Adams, R.M. $J$. Org. Chem. 1971, 36, 2388-2389. (b) Lane, C. F. J. Org. Chem. 1974, 39, $1437-$ 1438. (c) Brown, H.C.; Mandal, A.K.; Kulkarni, S.U. J. Org. Chem. 1977, 42, 1392-1398.

(5) Brown, H.C.; Subba Rao, B.C. J. Am. Chem. Soc. 1959, 81, 6423-6428.

(6) Brown, H.C.; Mandal, A.K. J. Org. Chem. 1992, 57, 4970-4976.

(7) Zaidlewicz, M.; Kanth, J.V.B.; Brown, H.C. J. Org. Chem. 2000, 65, 6697-6702.

(8) Brown, H.C.; Zaidlewicz, M.; Dalvi, P.V.; Biswas, G.K. J. Org. Chem. 2001, 66, 4795-4798.

(9) Crich, D.; Neelamkavil, S. Org. Lett. 2002, 4, 4175-4177.

(10) Crosby, G.A. US Pat., 1975, 3,928,293.

(11) Domb, A.; Avny, Y. J. Macromol. Sci. Part A pure Appl. Chem. 1985, 22, 167181.

(12) Domb, A.; Avny, Y. J. Appl. Polym. Sci. 1985, 30, 3589-3604.

(13) Domb, A.; Avny, Y. J. Macromol. Sci. Part A pure Appl. Chem. 1985, 22, 183201.

(14) Rajasree K.; Devaky, K.S. J. Appl. Polym. Sci. 2001, 82, 593-600.

(15) See, for example: (a) Smith, K. Solid Supports and Catalysts in Organic Synthesis, Ellis Harwood, Chichester, UK, 1992. (b) Smith, K. Selectivity through the use of Heterogeneous Catalysts, In Supported Catalysts and Their Applications, ed. Sherrington, D.C.; Kybett, A.P. The Royal Society of Chemistry, Cambridge, 2001, pp. 233-241. (c) Delaude, L.; Laszlo, P.; Smith, K. Acc. Chem. Res. 1993, 26, 607-613. (d) Smith, K. Ajarim, M.D.; El-Hiti, G.A. Catal. Lett. 2010, 134, 270-278. (e) Smith, K.; Ajarim, M.D.; El-Hiti, G.A. Top. Catal. 2009, 52, 16961700. (f) Smith, K.; El-Hiti, G.A. Curr. Org. Chem., 2006, 10, 1603-1625. (g) Smith, K.; El-Hiti, G.A. Curr. Org. Synth. 2004, 1, 253-274. (h) Smith, K.; Ewart, G.M.; El-Hiti, G.A.; Randles, K. R. Org. Biomol. Chem. 2004, 2, 3150-3154. (i) Smith, K.; Roberts, S.D.; El-Hiti, G.A. Org. Biomol. Chem. 2003, 1, 1552-1559. (j) Smith, K.; El-Hiti, G.A.; Jayne, A.J.; Butters, M. Org. Biomol. Chem. 2003, 1, 2321-2325. (k) Smith, K.; El-Hiti, G.A.; Jayne, A.J.; Butters, M. Org. Biomol. Chem. 2003, 1, 1560-1564. (l) Smith, K.; Liu, C.-H. Chem. Commun. 2002, 886- 
887. (m) Smith, K.; Almeer, S.; Peters, C. Chem. Commun. 2001, 2748-2749. (n) Smith, K.; El-Hiti, G.A.; Hammond, M.E.W.; Bahzad, D.; Li, Z.; Siquet, C. J. Chem. Soc., Perkin Trans. 1 2000, 2745-2752. (o) Smith, K.; Jones, D. J. Chem. Soc., Perkin Trans. 1 1992, 407-408.

See for example: reference 1 and (a) Smith, K. Organoboron Chemistry, in. Organometallics in Syntheses: Mannual, A. ed. Schlosser, M. 2nd ed., Wiley, Chichester, 2004, Chapter III, pp. 465-533. (b) Smith, K.; El-Hiti, G.A.; Hou D.; DeBoos, G.A. J. Chem. Soc., Perkin Trans. 1 1999, 2807-2812. (c) Pelter, A.; Smith, K.; Hutchings, M.G.; Rowe, K. J. Chem. Soc., Perkin Trans. 1 1975, 129138. (d) Pelter, A.; Hutchings, M.G.; Rowe, K.; Smith, K. J. Chem. Soc., Perkin Trans. 1 1975, 138-142. (e) Pelter, A.; Hutchings, M.G.; Smith, K. J. Chem. Soc., Perkin Trans. 1 1975, 142-145. (f) Pelter, A.; Hutchings, M.G.; Smith, K.; Williams, D.J. J. Chem. Soc., Perkin Trans. 1 1975, 145-150.

(17) For the synthesis of polymeric materials see, for example: (a) Marvel C.S.; Chambers, R.R. J. Am. Chem. Soc. 1948, 70, 993-998. (b) Marvel, C.S.; Aldrich, P.H. J. Am. Chem. Soc. 1950, 72, 1978-1981.

(18) Zweifel, G.; Brown, H.C. Org. React. 1963, 13, 1-54.

(19) Heal, H.G. J. Inorg. Nucl. Chem. 1960, 12, 255-258.

(20) Brown, H.C. Hydroboration, Benjamin, W. A. Inc., New York, 1962.

(21) Mincione, E. J. Org. Chem. 1978, 43, 1829-1830.

(22) (a) Lane, C.F.; Hyatt, H.L.; Daniels, J.; Hopps, H.B. J. Org. Chem. 1974, 39, 3052-3054. (b) Lane, C.F. Aldrichimica Acta. 1975, 8, 20-23. (c) Brown, H.C.; Choi, Y.M.; Narasimham, S. J. Org. Chem. 1982, 47, 3153-3163.

(a) Vogel's Textbook of Practical Organic Chemistry, 5th ed.; Longman: Harlow, 1989. (b) Perrin, D.D.; Armarego, W.L.F. Purification of Laboratory Chemicals, 3rd ed.; Pergamon: Oxford, 1988.

(24) Brown, H.C.; Kramer, G.W.; Levy, A.B.; Midland, M.M. Organic Syntheses via Boranes, Wiley-Interscience, New York, 1975. 
K. Smith et al.

Table 1 Preparation of borane adducts 8-12 from the corresponding polymeric sulfides 2-6 according to Scheme $1^{a}$

\begin{tabular}{lllll}
\hline Polymeric sulfide & Adduct $^{b}$ & $\mathrm{n}$ & $\mathrm{B} / \mathrm{S}$ ratio & $\mathrm{mmol} \mathrm{BH}_{3} / \mathrm{g}$ \\
\hline $\mathbf{2}$ & $\mathbf{8}$ & 3 & 0.68 & 8.17 \\
$\mathbf{3}$ & $\mathbf{9}$ & 4 & 0.65 & 6.69 \\
$\mathbf{4}$ & $\mathbf{1 0}$ & 5 & 0.65 & 5.85 \\
$\mathbf{5}$ & $\mathbf{1 1}$ & 6 & 0.67 & 5.36 \\
$\mathbf{6}$ & $\mathbf{1 2}$ & 8 & 0.68 & 4.44
\end{tabular}

${ }^{a}$ All adducts were prepared by passing diborane gas into a suspension of the polymeric sulfides (3 g) in dichloromethane $(20 \mathrm{~mL}) .{ }^{b}$ White powders at room temperature. ${ }^{c}$ Ratio of $\mathrm{BH}_{3}$ molecules (estimated by measurement of hydrogen evolved on hydrolysis in THF:glycerol:3 M HCl (1:1:1) to S atoms present (measured by microanalysis). 
Table 2 Hydroboration-oxidation of alkenes with the borane adduct 8 in THF according to Scheme 2 at room temperature for $4 \mathrm{~h}^{a}$

\begin{tabular}{lll}
\hline Alkene & Product & Yield (\%) $)^{b}$ \\
\hline 1-octene & 1-octanol & 59 \\
& 2-octanol & 2 \\
1-hexene & 1-hexanol & 71 \\
& 2-hexanol & 2 \\
cyclopentene & cyclopentanol & 80 \\
cyclohexene & cyclohexenol & 86
\end{tabular}

${ }^{a}$ Alkene $(9.0 \mathrm{mmol})$ was added to a solution of $\mathbf{8}\left(\mathrm{ca} .3 .6 \mathrm{mmol} \mathrm{BH}_{3}\right)$ in THF $(14 \mathrm{~mL})$ at $0-5{ }^{\circ} \mathrm{C}$ and stirred for $4 \mathrm{~h}$ at room temperature. The mixture was oxidised at $0-5{ }^{\circ} \mathrm{C}$ using $\mathrm{NaOH}(3.0 \mathrm{M}, 3.0 \mathrm{ml})$ and $\mathrm{H}_{2} \mathrm{O}_{2}(30 \%, 3.5 \mathrm{ml})$ followed by warming to room temperature for $1 \mathrm{~h}$ to ensure complete oxidation. ${ }^{b} \mathrm{By}$ GC analysis using hexadecane as internal standard. 
K. Smith et al.

Table 5 Hydroboration-oxidation of alkenes with the borane adduct $\mathbf{1 1}$ in THF at room temperature for $16 \mathrm{~h}^{a}$

\begin{tabular}{lll}
\hline Alkene & Product & Yield $(\%)^{b}$ \\
\hline 1-octene & 1-octanol & 77 \\
& 2-octanol & 4 \\
1-hexene & 1-hexanol & 73 \\
& 2-hexanol & 5 \\
styrene & 2-phenylethanol & 84 \\
& 1-phenylethanol & 13 \\
1-methylcyclohexene & trans-2-methylcyclohexanol & 83 \\
cyclopentene & cyclopentanol & 88 \\
${ }^{a}$ Alkene $(9.0$ mmol $)$ was added to a solution of $\left.\mathbf{1 1}(\mathrm{ca} .3 .6 \mathrm{mmol} \mathrm{BH})_{3}\right)$ in THF $(15 \mathrm{~mL})$ at \\
$0-5{ }^{\circ} \mathrm{C}$ and was stirred for 30 min at $0{ }^{\circ} \mathrm{C}$ and for $16 \mathrm{~h}$ at room temperature. The reaction \\
mixture was oxidised at $0-5{ }^{\circ} \mathrm{C}$ using NaOH $(3.0 \mathrm{M}, 3.0 \mathrm{~mL})$ and $\mathrm{H}_{2} \mathrm{O}_{2}(30 \%, 3.5 \mathrm{~mL})$ \\
followed by warming to room temperature for $1 \mathrm{~h} \mathrm{to} \mathrm{ensure} \mathrm{complete} \mathrm{oxidation.}{ }^{b} \mathrm{By} \mathrm{GC}$ \\
analysis with hexadecane as an internal standard.
\end{tabular}


Table 6 Reduction of some carbonyl compounds with borane adduct $\mathbf{1 1}$ in $\mathrm{THF}^{a}$

\begin{tabular}{lllll}
\hline Entry & Starting material & $\mathbf{1 1}$ (mol. eq.) & Product & Yield (\%) \\
\hline 1 & benzaldehyde & 0.4 & benzyl alcohol & 100 \\
2 & 2-hexanone & 0.4 & 2-hexanol & 84 \\
3 & caproic acid & 1.1 & 1-hexanol & 93 \\
4 & ethyl benzoate & 0.8 & benzyl alcohol & 94 \\
${ }^{a}$ Carbonyl compound $(5.0 \mathrm{mmol})$ was added to a solution of $\mathbf{1 1}$ in THF and stirred at $0{ }^{\circ} \mathrm{C}$ \\
for 30 min and refluxed for $4 \mathrm{~h}$. Methanol $(3 \mathrm{~mL})$ was added and the mixture was stirred \\
for 15 min then extracted with diethyl ether $(20 \mathrm{~mL}) .{ }^{b}$ By GC analysis using hexadecane \\
as internal standard.
\end{tabular}


K. Smith et al.

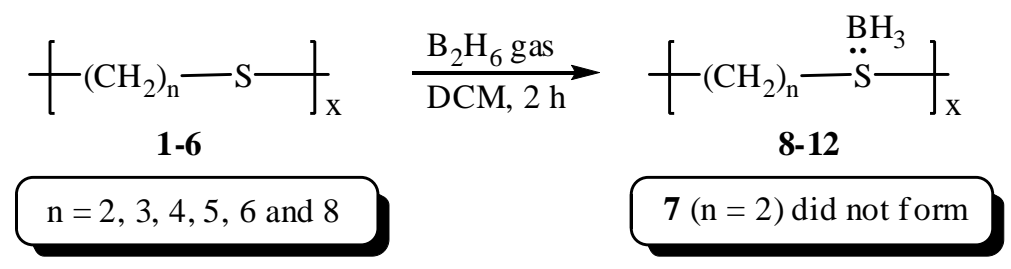

Scheme 1. Synthesis of the polymeric sulfide-borane adducts 8-12. 


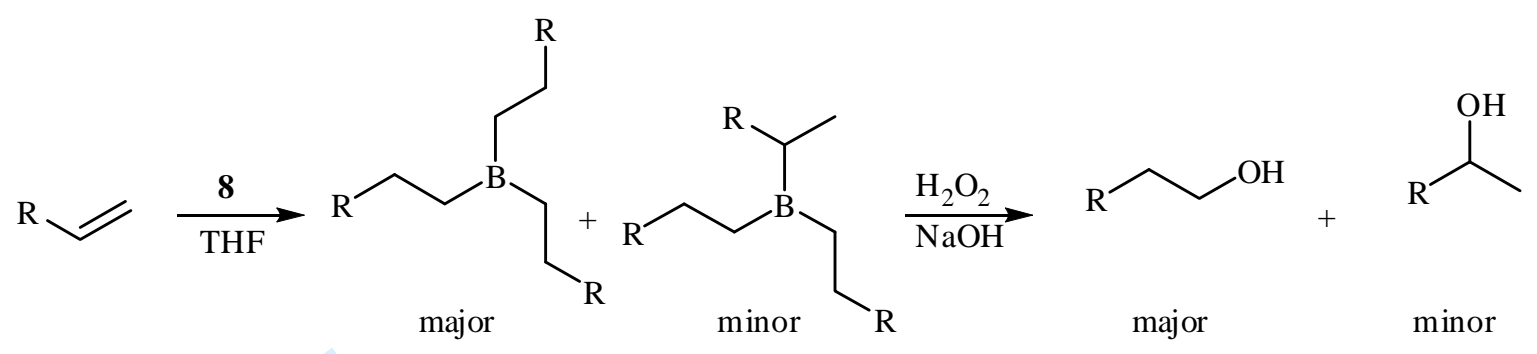

Scheme 2. Hydroboration-oxidation of alkenes with the borane adduct 8 . 
K. Smith et al.

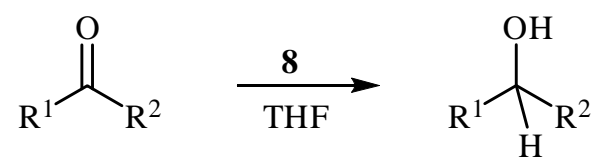

Scheme 3. Reduction of aldehydes and ketones with the borane adduct 8 . 


\section{List of Schemes Captions}

Scheme 1. Synthesis of the polymeric sulfide-borane adducts 8-12.

Scheme 2. Hydroboration-oxidation of alkenes with the borane adduct 8 .

Scheme 3. Reduction of aldehydes and ketones with the borane adduct 8. 